\title{
Thai Nurses' Learning Needs Regarding Disaster Nursing: High Needs?
}

\author{
Kirana Phakdeechanuan ${ }^{1}$, Praneed Songwathana ${ }^{2}$, Wipa Sae-Sia ${ }^{3}$
}

\begin{abstract}
Background: Disaster nursing has become a critical concern, worldwide, due to a trend toward management strategy. However, limited studies are conducted in Thailand where nurses have faced increasing threat to both natural and man-made disasters.

Purpose: To describe the amounts of learning needs (both expressed and normative needs) regarding disaster nursing among Thai nurses.

Methods: The sample included 454 registered nurses who have been working in Thailand for at least six months selected through the multi-stage sampling methods. Data were collected using questionnaire included the Learning Needs Regarding Disaster Nursing Questionnaire (LNDNQ), developed based on the learning needs triangle model and the concept the International Council of Nurses (ICN) Framework of Disaster Nursing Competencies. The LNDNQ was tested for content validity by three experts and for reliability with 20 nurses using Cronbach's alpha coefficient yielding a value of .97 (expressed needs), and .99 (normative needs), respectively. Data were analyzed by descriptive statistics.

Result: This study found that the top three contents of the most learning needs in expressed needs were similarly with the most normative needs which items were related to mitigation/prevention and response phase. The most learning needs they expressed were assisting and first aid for victims at the scene $(n=229,50.4 \%)$, followed by basic principle of triage $(\mathrm{n}=218,48.0 \%)$, and training of the disaster nursing management plans $(n=217,47.80 \%)$. However, the top least expressed needs were related to mitigation/prevention and recovery/rehabilitation phase. These were providing an information for community with the notification, and announcement the severity level of disaster $(n=32,7.0 \%)$, followed by preparing and organizing the evacuation area for victims $(\mathrm{n}=37,8.1 \%)$.

Conclusion: The contents related to the most learning needs (expressed needs and normative needs) regarding disaster nursing must be emphasized in training course and nursing curriculums in Thailand to improve Thai nurses' capability in disaster nursing management.
\end{abstract}

Keywords: nurses, disaster nursing, learning needs

1 Nursing Science Student, Faculty of Nursing, Prince of Songkla University, Thailand.

Email: a_zinniajung@ hotmail.com

2 Associate Professor, Faculty of Nursing, Prince of Songkla University, Songkhla, Thailand.

3 Assistant Professor, Faculty of Nursing, Prince of Songkla University, Thailand. 


\section{BACKGROUND}

Disaster is a global concern nowadays as the increasing numbers of disaster events are occurring more frequently and severity around the world particularly in Asia. It was reported that disaster in Asia accounts for 44.6 percent occurrences (Asian Disaster Reduction Center [ADRC], 2013). Deaths, psychological problems, loss of properties, social, and environmental issues are all caused by disaster events.

Several disasters have occurred elsewhere often lead to the significant damage to the community. For example, natural disasters that frequently occur in Thailand include floods, droughts, tropical cyclones, thunderstorms, storm surges, forest fires, earthquakes and landslides, while man-made disasters as terrorism and protest occur occasionally (Thai Meteorological Department (TMD), 2014). Then, the frequent and severity of disasters has brought community people especially national and international attention to develop a better plan for disaster preparedness and management. With effective disaster management, it will decrease disaster damage (Al Khalaileh, Bond \& Alasad, 2012; Jennings-Sanders, 2004; Julawong, 2011).

When disaster occurs, nurses, in particular, are the largest groups of committed health personnel who often work in difficult situations with limited resources. Therefore, it is important for all nurses to be prepared as they play the critical role in disaster phases (Yin, He, Arbon, Zhu, Tan \& Zhang, 2011). The International Council of Nurses (ICN) and Nursing Coalition for Mass Casualty Education (INCMCE) then proposed that nurses should be ready with the basic knowledge and skill to cope with disaster events (ICN, 2009; INCMCE, 2003). The disaster nursing competencies is essential. As ICN proposed a disaster management continuum model throughout the three disaster phases, four competencies are required for nurses. This has necessitated all nurses to increase awareness about disaster nursing and development of knowledge and expertise related to disaster education at workforce (Hammad, Arbon \& Gebbie, 2011; Spain, Clements, DeRanieri \& Holt, 2014; Pattillo, 2006; Yin, He, Arbon, Zhu, Tan \& Zhang, 2012). However, previous literature reviews showed that the majority of nurses were not well prepared in disaster management (Hammad, Abon \& Gebbie, 2011; Julawong, 2013; Slepski, 2007; Yang, Xiao, Cheng, Zhu \&Arbon 2010; Yin, He, Arbon, Zhu, Tan \& Zhang, 2012).

Regarding the disaster nursing is not fully incorporated to nursing curricular in nursing education of Thailand, the crucial stage in the educational process that leads to changes in practice is suggested to assess the learning needs (Grant, 2002; Forbes, While \& Ullman, 2006).Individual learning needs assessment is a focus in the study to be used as the basic information for forming a routine part of training, learning, and improving practice that balance which individual needs (Grant, 2002). Therefore, a better understanding of nurses learning needs for disaster nursing is essential for developing a disaster nursing course or program that meet the need (Loke \& Fung 2014). However, disaster education in Thailand has not been evident in terms of integrating the content in nursing curriculum or offering as additional training. Previous studies showed that there were lacked of disaster nursing program and inadequate training offered in existing Thai nursing curriculum (Julawong, 2011; Popattanachai, Sarakshetrin, Chantra, \&chipha, 2011). There was also little consensus regarding the content of disaster nursing. 
Moreover, the disaster nursing courses in Thailand provided the skill trainings which are specific to triage, suturing and CPR (cardio pulmonary resuscitation) which may be not enough for nurses to manage all phases of disaster. Furthermore, the perception of Thai nurses own learning needs in supporting the effectiveness in disaster management has not been assessed. According to the definition of the learning needs in context of nurses' roles by Forbes, While, and Ullman (2006), expressed needs refer to the nurse requirements of their nursing roles which turned into actions and normative needs refer to the needs of teams or services which are defined by the nursing organization that want nurses to learn more. Hence, to improve Thai nurses' capability in disaster nursing management, it is required to explore learning needs both expressed and normative needs regarding disaster nursing among nurses who have significance role in disaster management.

The conceptual framework of this study was constructed based on 1) the learning needs triangle model (Forbes, While, \& Ullman, 2006), 2) the disaster nursing competencies based on the International Council of Nurses Framework of Disaster Nursing Competencies (WHO \& ICN, 2009). First, the learning needs triangle model developed by Forbes, While, and Ullman (2006) for assessing the learning needs of nurses, defined the learning needs in three domains namely 1 ) Expressed needs refer to the nurse requirements of their nursing role which turned into actions; 2) Felt needs refer to the needs of target patient population such as patients want nurses to learn more to improve the performances, and 3) Normative needs refer to the needs of team or service which is defined by the health care organization of nurses that want nurses to learn more. However, it is essential to explore the nurse's needs which include expressed needs and normative needs except felt needs. As the expressed needs are identified by nurses about what they already have but required more to fulfill their role, and normative needs identified by the organization of nurse, whereas felt needs is an individual feeling of another person which nurses perceived.

Second, content related to disaster nursing derived from the conceptualization of International Council of Nurses Framework of Disaster Nursing Competencies (WHO $\&$ ICN, 2009). The ICN Framework of Disaster Nursing Competencies developed for general nurse has also been widely used at an international level (Loke\& Fung, 2014) because it helps clarify the nurses' role in disaster and guides the development of disaster training and educator. The main contents of ICN Framework of Disaster Nursing Competencies were organized under four competencies of disaster management as, mitigation/prevention and preparedness competencies in pre-disaster phase, response competencies in disaster phase, recovery/rehabilitation competencies in post-disaster (ICN \& WHO, 2009). To reflect the professional update, the learning needs of hospital nurses in Thailand regarding disaster nursing in all phases will be significant to explore. However, this study focused on the expressed needs and normative needs to ensure the equality of those needs reported by nurses which is not a feeling by other persons.

\section{OBJECTIVE}

The objective of this study was to describe the amounts of learning needs (both expressed and normative needs) regarding disaster nursing among Thai nurses. 


\section{METHODS}

\section{Population and Setting}

The target population in this study was registered nurses who have been working in the selected provincial hospitals and community hospital, Thailand. The following five selected provinces were Changmai, Khonkaen, Chonburee, Songkhla, and Bangkok. The following inclusion criteria were used to recruit participants in this study 1) licensed as a registered nurse $(\mathrm{RN}), 2$ ) have been working in provincial hospitals and community hospital for at least 6 months, and 3) is willing to participate.

The research used a proportion of the known population to determine the sample size for this study. Regarding Bureau of Policy and Strategy in Thailand reported in 2012, the total numbers of Thai registered nurses who have been working in provincial hospitals, community hospital are about 80,250. According to Singchangchai, Khampalikit, and Na-Sae (1996), if the size of a population was about 10,000, approximately $1 \%$ of them should be included. Thus, 802 participants were required. To overcome any incidences of incomplete returned questionnaires from the subjects, $20 \%$ of participants were added to the sample. Thus, 962 potential participants were initially approached. In this study, the actual number of responses was only 454 accounting of $50 \%$.

\section{Ethical Consideration}

This study was conducted with the intention of protecting the human rights of all subjects. Prior to data collection, consent was obtained. The research proposal and instruments were approved by the Research Ethics Committee, Faculty of Nursing, Prince of Songkla University (PSU), Thailand, including permission for data collection from the directors of the selected provincial hospitals and school of nursing in universities.

\section{Instrumentation}

The self-report questionnaire composed of: 1) a Demographic Data and Work Experience Questionnaire (DDWEQ) and 2) Learning Needs Regarding Disaster Nursing Questionnaire (LNDNQ) were used. The DDWEQ consists of 13 items including age, region, classification of hospital, gender, marital status, religion, education level, work status, work unit, nurse's experience, experience in assisting disaster victims, previous attending in disaster nursing training program, previous attending in disaster drill activity, opinion with disaster nursing, and previous understanding about the ICN Framework of the Disaster Nursing Competencies.

The LNDNQ was developed by researcher based on the learning needs triangle model of Forbes, While, and Ullman (2006) and add the contents of disaster nursing competencies based on the International Council of Nurses Framework of Disaster Nursing Competencies (2009) which is the framework of this study. This instrument was consisted of two subscales of need: expressed needs and normative needs. There are 40 items which divided into 4 areas: 1) prevention and mitigation area (16 items), 2) preparedness area (7 items), 3) response area (12 items), and 4) recovery and rehabilitation area (5 items). Each item was rated by using a 3-point Likert scale ranging 
from "1" (not needed), "2" (needed), “3" (most needed). The possible score was ranged from 40 to 120 . For interpretation, higher score means higher nurses' learning needs.

The LNDNQ was tested for the clarity, validity, and appropriateness of the language used by three experts. The item content validity index (I-CVI) and scale content validity index $(\mathrm{SCVI})=.88$. The internal consistency of this questionnaire was tested with 20 nurses yielding a value ofCronbach's alpha coefficient at .97 (expressed needs), and .99 (normative needs), respectively.

\section{Data analysis}

Descriptive statistics, summarized as frequencies, percentages, means, standard deviations, were used to describe the demographic and determine the particular contents of nurses' learning needs regarding disaster nursing among Thai nurses.

\section{RESULT}

\section{Demographic Data and Disaster Experiences (DDDEQ)}

The mean age of 454 participants was 37 years old. Majority of them were female (94.5\%) and Buddhist (89.7\%). More than half (61\%) worked at IPD ward (in-patient department) and at the provincial hospital (62.8\%). Regarding to participant's previous experiences, more than half of the participants $(65 \%)$ did not have direct experience in assisting disaster victims, but they used to attend disaster management training program (69.6\%). Approximately $70 \%$ of them used to attend hospital disaster drill which provided by their working unit or hospital. Among those who were currently trained in disaster, content in the chemical disaster was the most experience $(30.4 \%)$, followed by disaster related to fire $(18.7 \%)$. On the contrary, almost of the participants reported that disaster nursing is an important skill $197.4 \%$ ( whereas more than half of them $(57 \%)$ have not known or understood about the ICN Framework of the Disaster Nursing Competencies before. The number and percentage of nurses' demographic are shown in Table 1.

Table1. Number and Percentage of Nurses' Demographic Characteristics $(N=454)$

\begin{tabular}{lrr}
\hline Characteristics & $\mathrm{n}$ & $\%$ \\
\hline Age (years) $(\mathrm{M}=37.37, \mathrm{SD}=9.63$, Min = 22, Max = 59) & & \\
$20-30$ & 145 & 31.9 \\
$31-40$ & 158 & 34.8 \\
$40-50$ & 96 & 21.1 \\
$\quad>50$ & 55 & 12.1 \\
Gender & & \\
Female & 430 & 94.5 \\
Male & 24 & 5.3 \\
Marital status & & \\
Single & 178 & 39.1 \\
Married & 255 & 56.0 \\
Divorce/separate & 15 & 3.3 \\
\hline
\end{tabular}




\begin{tabular}{lrr}
\hline Characteristics & $\mathrm{n}$ & $\%$ \\
\hline Religion & & \\
Buddhist & 408 & 89.7 \\
$\quad$ Islam & 42 & 9.2 \\
Christian & 4 & 0.9 \\
Classification of hospital & 169 & 37.2 \\
$\quad$ Community hospital & 285 & 62.8 \\
$\quad$ Provincial hospital & & \\
Work unit & 278 & 61.4 \\
IPD & 98 & 21.6 \\
ER & 73 & 16.0 \\
OPD & 5 & 1.0 \\
Other & 295 & 65.0 \\
No & 159 & 35.0 \\
Yes & & \\
Attending in disaster management training program & 138 & 30.4 \\
No & 316 & 69.6 \\
Yes & & \\
Attending in hospital disaster drill & & \\
No & 136 & 30.0 \\
Yes & 318 & 70.0 \\
Disaster nursing is an important skill & & \\
No & & \\
Yes & & \\
Knowing/understanding about the ICN Framework of the & 12 & 2.6 \\
Disaster Nursing Competencies & 442 & 97.4 \\
$\quad$ No & & \\
Yes & & 57.0 \\
& & \\
\hline
\end{tabular}

\section{The Items with the Most Learning Needs (Both Expressed and Normative Needs) Regarding Disaster Nursing}

The table 2 showed the items with the most frequency and percentage of expressed and normative needs regarding disaster nursing among Thai nurses in each disaster phase. When classified in each disaster phase (Table2), it was found in the pre-disaster phase were training of the disaster nursing management plans had the highest needs $(n=217$, $47.80 \%$ ), followed by giving the value, accepting the difference, and also recognizing the dignity of each individual victim $(\mathrm{n}=185,40.7 \%)$. Likewise, assisting and first aid for victims at the scene $(n=229,50.4 \%)$ was reported as the top item with learning needs in the disaster phase. Moreover, nurses expressed their learning need in the post-disaster phase was providing the rehabilitation for victims at an individual level $(n=154,33.9 \%)$. 
Table 2 also showed the top overall items that nurses reported their normative needs in each disaster phase. When classified in each phase, it was found that the highest number of nurses' learning needs they perceived by organization were training of the disaster nursing management plans $(n=252,55.5 \%)$, followed by keeping confidentiality of the communications and data recording of victims $(n=210,46.3 \%)$ in pre-disaster phase. In disaster phase, the nurse reported that assisting and first aid for victims at the scene $(\mathrm{n}=259,57.0 \%)$ were most normative needs. Additionally, in the post-disaster phase, the highest number of nurses' learning needs they perceived by organization were providing the rehabilitation for victims in individual level $(n=196,43.2 \%)$.

Table 2. The Items with the Most Frequency and Percentage of Expressed and Normative needs Regarding Disaster Nursing Among Thai Nurses in Each Disaster Phase $(N=454)$

\begin{tabular}{ccc}
\hline Disaster phase & Learning Needs & $\mathbf{n}(\%)$ \\
\hline
\end{tabular}

\section{The top items with the most expressed needs}

1. Pre-disaster

- Mitigation/

prevention

- Preparedness

2. Disaster

- Response

3. Post-disaster

- Recovery/

rehabilitation
- Training of the disaster nursing management plans

- Giving the value, accepting the difference, and also recognizing the dignity of each individual victims

- Assisting and first aid for victims at the scene

- Providing the rehabilitation for victims in individual level.
217(47.8)

185(40.7)

$229(50.4)$

154(33.9)

The top items with the most normative needs

1. Pre-disaster

- Mitigation/

prevention

- Training of the disaster nursing

$252(55.5)$ management plans

- Preparedness

- Keeping confidentiality of the

210(46.3) communications and data recording of victims

2. Disaster

- Response

- Assisting and first aid for victims at the

$259(57.0)$ scene

3. Post-disaster

- Recovery/ rehabilitation
- Providing the rehabilitation for victims in individual level. 


\section{The Items with the Least Learning Needs (Both Expressed Needs and Normative Needs) Regarding Disaster Nursing Among Thai Nurses}

The item analysis was also performed to describe the least learning needs regarding disaster nursing (Table 3). When classified in each disaster phase, it was found that the lowest number of nurses' learning needs in pre-disaster phase were preparing for supporting or assisting the vulnerable groups $(n=69,15.2 \%)$, followed by preparing the needed equipment the individual, community, agency and organizations for preparing to deal with disaster $(n=40,8.8 \%)$.Moreover, nurses conveyed as the least expressed needs in response during disaster phase regarding assisting the victims followed by Psychological First Aid concept $(n=44,9.7 \%)$. Furthermore, conducting research in disaster management $(n=76,16.7)$ in post-disaster phase were reported as the least needs by nurses.

In addition, the top three items nurses reported as the least normative needs were also described in each phase. Regarding pre-disaster phase, the lowest number of nurses' learning needs were training and assisting the vulnerable groups $(n=51,11.2 \%)$, followed by management or assisting the victims regardless to equality or entitlement of each individual $(n=26,5.7 \%)$, and understanding the social status, culture, and belief of victims and the community $(n=26,5.7 \%)$.In the disaster phase, nurses also reported the least normative needs were assisting the victims using psychological first aid concept $(\mathrm{n}=24,5.3 \%)$. In the last disaster phase namely, post-disaster phase, developing the volunteer and community system for recovering health and coping with disasters of all types $(n=54,11.9 \%)$ were reported as the least needs.

Table 3. The Items with the Least Frequency and Percentage of the Expressed needs and Normative Needs Regarding Disaster Nursing Among Thai Nurses in Each Disaster Phase $(N=454)$

\begin{tabular}{|c|c|c|}
\hline Disaster phase & Learning Needs & $\mathrm{n}(\%)$ \\
\hline \multicolumn{3}{|c|}{ The top item with the least expressed needs } \\
\hline \multicolumn{3}{|c|}{ 1. Pre-disaster } \\
\hline $\begin{array}{l}\text { Mitigation/ } \\
\text { prevention }\end{array}$ & $\begin{array}{l}\text { - Preparing for supporting or assisting the } \\
\text { vulnerable groups }\end{array}$ & $69(15.2)$ \\
\hline - Preparedness & $\begin{array}{l}\text { - Preparing the needed equipment for individual, } \\
\text { community, agency and organizations for } \\
\text { preparing to deal with disaster }\end{array}$ & $40(8.8)$ \\
\hline \multicolumn{3}{|l|}{ 2. Disaster } \\
\hline - Response & $\begin{array}{l}\text { - Assisting the victims follow Psychological First } \\
\text { Aid concept }\end{array}$ & $44(9.7)$ \\
\hline \multicolumn{3}{|l|}{ 3. Post-disaster } \\
\hline $\begin{array}{l}\text { - Recovery/ } \\
\text { rehabilitation }\end{array}$ & - Conducting a research in disaster management & $76(16.7)$ \\
\hline \multicolumn{3}{|c|}{ The top item with the least normative needs } \\
\hline $\begin{array}{l}\text { - Mitigation/ } \\
\text { prevention }\end{array}$ & - Training the assisting the vulnerable groups & $51(11.2)$ \\
\hline
\end{tabular}


- Preparedness

- Management or assisting the victims with 26(5.7) regardless to an equality and entitlement of each individual

- Understanding in the social status, culture, and belief of victims and the community.

\section{Disaster}

- Response

\section{Post-disaster}

- Recovery/ rehabilitation

- Assisting the victims follow Psychological First

- Aid concept

- Developing the volunteer and community system for recovering health and coping with disasters of all types

54(11.9)

\section{DISCUSSION}

The result showed that the majority of Thai nurses reported their most learning needs were assisting and first aid for victims at the scene in the disaster phase which was similar to the normative needs reported by nurses. Therefore, the most learning needs regarding disaster nursing among Thai nurses was highlighted in the discussion of this study. Nurses are often the first of medical personnel who have to be actively involved in all phases of disaster situation. Therefore, to have essential knowledge and sufficient disaster nursing skills, ICN currently recommended that disaster nursing is encouraged to be learned and included in the nursing curriculum.

In generally, the basic nursing education in Thailand does not provide nurses with special knowledge, skill, or training for disaster management. The content and skills were mainly focused on emergency nursing such as triage, suturing, and CPR (cardiopulmonary resuscitation) which may be inadequate for nurses to manage all phases of disaster ( Julawong, 2011; Popattanachai et al., 2011). However, the disaster nursing content in the disaster phases was the most learning both expressed needs and normative needs among Thai nurses.

Disaster nursing in the disaster phase which require management skills in limited resources so that nurses who work in this phase must have the essential knowledge and sufficient assessment skills, triage, and monitors for physical and mental health issues, and provide appropriate care (ICN \& WHO, 2009). Previous studies indicated that not only education but also continued training and actual previous experience which disasters or shelters are extremely important factors which can increase knowledge, skill, and self-confidence in abilities to respond to disaster events among nurses (Baack \& Alfred, 2013; Loke \& Fun, 2014). This study also showed that about two third of Thai nurses did not have experience in assisting disaster victims and had been working at in-patient department ward which has a low chance to face with disaster event. In addition, the lack of direct disaster nursing experience among Thai nurses may limit their learning need regarding disaster nursing. 
The strengths of the findings were participants selected from hospitals in all regions of Thailand which can be generalized for Thailand at some levels although the actual number was not high as expected. In addition, the content was developed from the ICN which can be used for reflecting the nurses' learning needs and raising issues of disaster nursing education.

However, there are some limitations of this study that should be mentioned. First, most of the nurses had been mainly working in the provincial hospital, thus, it could not be generalized to nurses working in the community hospital. Secondly,this study used a single method of self-report to collect data which cannot control the time duration for each participant to complete all answers in the questionnaire which might affect the actual responses.

\section{CONCLUSION}

It can be seen that disaster nursing contents in disaster phase which had the highest number of nurses' learning needs they expressed were assisting and giving first aid for victims at the scene. Thus, this finding should receive the utmost attention from the nursing institution and health organizations in Thailand. To increase the disaster nursing knowledge and skill among Thai nurses, providing adequate disaster nursing education, training and skill by the organization and nursing institution can help.

\section{ACKNOWLEDGEMENTS}

The researchers gratefully acknowledge the contributions of the nurses who took part in this research. This study was partially funded by Research Center for Caring and Healing System for People with Trauma, Emergency and Disaster, Faculty of Nursing, Prince of Songkla University, and Graduate School, Prince of Songkla University, Hatyai, Songkhla, Thailand.

\section{REFERENCES}

Asian Disaster Reduction Center [ADRC]. (2011). Asia - disaster statistics. Retrieved from

http://www.preventionweb.net/english/countries/statistics/index_region.php?rid= 4

Al Khalaileh, M. A., Bond, E., \& Alasad, J. A. (2012). Jordanian nurses' perceptions of their preparedness for disaster management. International EmergencyNursing, 20(1), 14-23.

Baack, S., \& Alfred, D. (2013).Nurses' preparedness and perceived competence in managing disasters. Journal of Nursing Scholarship, 45(3), 281-287.

Bureau of Policies and Strategy, Permanent Secretary Offices, Ministry of Public Health, Thailand. (2012). Report on public health resource, 2012. Retrieved from http://thcc.or.th/download/gishealth/gishealth55.pdf

Forbes, A., While, A., \& Ullman, R. (2006). Learning needs analysis: The development of a tool to support the on-going professional development of multiple sclerosis specialist nurses. Nurse Education Today, 26(1), 78-86.

Grant, J. (2002). Learning needs assessment: Assessing the need. British Medical Journal, $\quad 324(7330), 156-159$. 
Hammad, K. S., Arbon, P., \&Gebbie, K. M. (2011). Emergency nurses and disaster response: an exploration of South Australian emergency nurses' knowledge and perceptions of their roles in disaster response. Australasian Emergency Nursing Journal, 14(2), 87-94.

International Nursing Coalition for Mass Casualty Education [INCMCE]. (2003). Educational competencies for registered nurses responding to mass casualty incidents. Retrieved from file:///C:/Users/admin/Documents /INCMCECompetencies.pdf

International Council of Nurses [ICN] \& World Health Organization [WHO], (2009).ICN framework of disaster nursing competencies. Geneva: International Council of Nurses

International Federation of Red Cross and Red Crescent Societies (IFRC) (2013). What is a disaster? Retrieved from https://www.ifrc.org/en/what-we-do/disastermanagement /about-disasters/what-is-a-disaster/

Jennings-Sanders, A. (2004). Teaching disaster nursing by utilizing the Jennings disaster nursing management model.Nurse Education in Practice, 4(1), 69- 76.

Julawong, O. (2013). Nursing preparedness in the royal Thai Army Nursing College.Journal of The Royal Thai Army Nurse, 14(1), 1-7.

Loke, A. Y., \& Fung, O. W. M. (2014). Nurses' competencies in disaster nursing: Implications for curriculum development and public health. International Journal of Environmental Research and Public Health, 11(3), 3289-3303.

Pattillo, M. (2006).Teaching disaster nursing response using simulations. Clinical Simulation in Nursing Education, 2 (2), 49-51.

Popattanachai, U., Sarakshetrin, A., Chantra, R., \&Chipha, O. (2011). A development enrich curriculum for nursing competencies in tsunami area for student nurse. Journal of Nursing Division, 38(1), 4-15.

Singchangchai, P., Kampalikit, S., \& Na-Sae, T. (1996). Nursing research: Principle and process (2nd ed.). Songkhla: Tame printing. (in Thai)

Slepski, L. A. (2007). Emergency preparedness and professional competency among health care providers during hurricanes Katrina and Rita: pilot study results. Disaster Management \& Response, 5(4), 99-110.

Spain, K. M., Clements, P. T., DeRanieri, J. T., \& Holt, K. (2012). When disaster happens: Emergency preparedness for nurse practitioners. The Journal for Nurse Practitioners, 8(1), 38-44.

Yang, Y. N., Xiao, L. D., Cheng, H. Y., Zhu, J. C., \&Arbon, P. (2010). Chinese nurses' experience in the Wenchuan earthquake relief. International Nursing Review, 57(2), 217-223.

Yin, H., He, H., Arbon, P., Zhu, J., Tan, J., \& Zhang, L.(2012). Optimal qualifications, staffing and scope of practice for first responder nurses in disaster. Journal of Clinical Nursing, 21(1-2), 264-271. 